\title{
PENGARUH MEDIA AUDIO VISUAL TERHADAP MAHARAH AL-KITABAH
}

\author{
Almannah Wassalwa ${ }^{1}$, Masykuri Masykuri ${ }^{2}$, Hamidatul Iflah $^{3}$ \\ Universitas Ibrahimy Situbondo \\ 1* $\underline{\text { salwaelmanna90@gmail.com, }}{ }^{2}$ masykuri.ismail@gmail.com
}

\begin{abstract}
:
This research to find out if audio visual media to writing skills in grade $V$ students Mi Miftahul Ulum. The use of audio visual media has a very important role that is: can provide many benefits as long as teachersplay an important role in the learning processs, in the study more focused on learning Arabic language in class V MI Miftahul Ulum researchers use case studies of the influence of audio visual media in maharoh kitabah which currently uses audio visual as a learning medium, in use of course there is a very good influence and not in arabic language learning. And can be seen from the average value of maharoh kitabah using audiovisual learning media in grade $V$, maximal values reached 90 while the average class $V$ was 77.4 while based on thitung $=2,552$ and ttabel at $\dot{\alpha}=5 \%$ and $d F=25=0.413$ therefore $t$ count $\geq t$ table this indicates that $2,552 \geq 0.413$.
\end{abstract}

Keywords: Media Audio Visual, Maharoh Kitabah

\section{PENDAHULUAN}

Di zaman milenial ini manusia tidak bisa jauh dari dunia teknologi, maka dari itu media audio visual yang cocok pada zaman sekarang. Siswa bisa menggunakan teknologi sesuai kebutuhan dalam proses pembelajaran dan guru bisa menggunakan teknologi sebagai media pembelajaran. Media pembelajaran adalah perantara atau pengantar pesan dari pengirim ke penerima pesan. ${ }^{1}$

Penggunaan media pembelajaran dalam proses belajar mengajar dapat membangkitkan keinginan dan minat yang baru, membangkitkan motivasi dan membuat rangsangan kegiatan belajar, dan bahkan membawa pengaruh-pengaruh psikologis terhadap siswa. Penggunaan media pembelajaran pada tahap orientasi pembelajaran akan sangat membantu keefektifan proses pembelajaran dan penyampaian pesan dan isi pembelajaran pada saat itu. Selain membangkitkan motivasi dan minat siswa, media pembelajaran juga dapat membantu meningkatkan pemahaman siswa. ${ }^{2}$

\footnotetext{
${ }^{1}$ Musfiqon. 2012. Pengembangan Media \& Sumber Pembelajaran. (Jakarta: Prestasi Pustaka Publisher). 27

2 Azhar Arsyad, Media Pembelajaran, (Jakarta: PT Rajagrafindo Persada.2011), 15-16
}

Dalam pengembangan media pembelajaran mengikuti perkembangan teknologi. Teknologi yang paling dimanfaatkan dalam proses belajar-mengajar adalah percetakan yang berdasarkan prinsip mekanis. Kemudian lahir teknologi audiovisual yang menggabungkan penemuan mekanis dan elektronik untuk tujuan pembelajaran. $^{3}$

Sebagai guru yang professional, guru harus menjadikan proses kegiatan belajar mengajar lebih menyenangkan dan lebih berkesan agar semua pelajaran yang telah diajarkan dapat diingat lebih lama menjadikan proses pembelajaran agar lebih menyenangkan dan berkesan guru dapat memulainya dari pengelolaan kelas, lalu strategi apa yang digunakan, metode, media ataupun lainnya.

Kemampuan seorang guru dalam menerapkan media pembelajaran masih dibilang sangat kurang, sesuai dengan materi ajar serta cenderung monoton karena media yang digunakan kurang tepat dan menyebabkan peserta didik tidak tertarik dengan penjelasannya. Media pembelajaran sebagai salah satu faktor alat penunjang yang

\footnotetext{
${ }^{3}$ Azhar Arsyad, Media Pembelajaran, 29
} 
dapat mempengarui aktivitas proses belajar mengajar.

Audio visual salah satu media yang dikembangkan dalam teknologi yang berupa mekanis dan elektronik untuk menyajikan pesan-pesan yang memiliki komponen perangkat keras didalamnya seperti mesin proyektor, film, tipe recorder dan proyektor visual sebagai cara dalam menyampaikan dan mengahsilkan output selama proses belajar mengajar. $^{4}$

Hasil observasi yang diperoleh pada siswa kelas V pembelajaran Bahasa Arab dengan penggunaan media audio visual yang digunakan oleh guru di sekolah Madrasah Ibtida'iyah Miftahul Ulum untuk mempermudah dalam memahami pembelajaran Bahasa Arab. Sehingga pembelajaran dapat berlangsung secara efektif dan tidak monoton dalam mencapai tujuan proses pembelajaran yang digunakan.

Penggunaan media audio visual yang dikembangkan proses pembelajaran di MI Miftahul Ulum Arjasa Sukowono disebabkan sistem proses pembelajaran berjalan secara monoton dan kurang efektif. Serta rendahnya kreativitas menulis siswa kelas $\mathrm{V}$ disebabkan oleh kurangnya pelatihan dalam peningkatan kretivitas menulis.

Penggunaan media dalam proses pembelajaran berlangsung membuat susasana kelas menjadi hidup, menyenangkan, tidak terkesan monoton sehingga mendorong memiliki semangat yang tinggi dalam proses pembelajaran. Hal tersebut disesuaikan dengan materi yang diajarkan.

Peggunaan media audio visual sangat penting dan banyak manfaat kepada guru sebagai alat untuk proses pembelajaran. Dalam penelitian ini memfokuskan pada pembelajaran Bahasa Arab kelas V MI dengan metode penetlian studi kasus pengaruh media audio visual dalam maharoh kitabah sebagai media pembelajaran, dalam penggunaanya ada pengaruh yang sangat baik atau tidak ada pengaruh sangat baik dalam pembelajaran Bahasa Arab.

Media visual adalah alat yang melibatkan panca indera. Media Visual

\footnotetext{
${ }^{4}$ Azhar Arsyad, Media Pembelajaran, 30
}

terdapat dua jenis pesan, diantaranya: verbal dan non verbal, sedangkan pesan verbal visual teridiri atas kata-kata (Bahasa verbal) dalam bentuk tulisan dan non verba visual. ${ }^{5}$

Media berbasis visual berperan sangat penting dalam proses belajar dalam mempermudah pemahaman dan ingatan serta dapat memberikan hubungan minat siswa, isi materi pelajaran dengan dunia nyata. ${ }^{6}$

Kemampuan menulis sebagai komponen dalam merangkai bahasa atau mengarang. $^{7}$ menulis adalah sebuah keterampilan berbahasa dalam menghasilkan sesuatu yang disebut tulisan yang dapat dipahami oleh pembaca. ${ }^{8}$

Aktivitas menulis sebagai bentuk dari perwujudan kemampuan dan keterampilan yang paling akhir dikuasai oleh pembelajar setelah kemampuan mendengar, berbicara, dan membaca. Kemampuan menulis lebih sulit dikuasai dibandingkan dengan tiga kemapuan yang lain bahkan oleh penutur asli Bahasa. Hal ini disebabkan kemampuan menulis memiliki berbagai unsur diluar bahasa yang disebut isi tulisan.

Menulis merupakan salah satu media berkomunikasi dengan dua orang yang terbatas oleh ruang dan waktu. ${ }^{9}$

\section{METODE PENELITIAN}

Pendekatan yang digunakan dalam penelitian ini dengan metode Kuantitatif yang mana pemaparan data dihasilkan berupa angka-angka dan bisa diperoleh penghitungan atau diperoleh dengan hasil pengukuran dan analisis statistik. $^{10}$

Jenis penelitian yang digunakan berupa ekperimen dengan menggunakan design One

\footnotetext{
5 Yudhi Munadi, Media Pembelajaran, (Jakarta: Refrensi GP Press Group), 2013,81

6 Azhar Arsyad, Media Pembelajaran, 91

7 A.S. Broto, pengajaran Bahasa Indonesia sebagai Bahasa Kedua di Sekolah Dasar Berdasarkan Pendekatan Linguistik Kontrastif, (Jakarta: Bulan Bintang), 1980, 141

8 Syaiful Mustofa, Strategi Pembelajaran Bahasa ArabInovatif (Malang: UIN Press), 2017, 83

9 Bisri Mustofa \& M. Abdul Hamid Metode dan Strategi Pembelajaran Bahasa Arab,(Malang, UIN Maliki Press, 2016), 104.
}

10 Sugiyono, Metode Penelitian Kuantitatif Kualitatif dan R\&D, (Bandung: Alfabeta, 2015) 3 
-Group Pretest - Postes Design. ${ }^{11}$ Penelitian ini menggunakan perlakuan dengan dua kali pengukuran. Pengeukuran sebelum dan sesudah diberikan treatmen. ${ }^{12}$ Dalam hal ini Untuk mencari pengaruh media audio visual terhadap terhadap maharoh kitabah siswa kelas V MI Miftahul Ulum Arjasa, Sukowono Jember.

Populasi seluruh kelas V MI Miftahul Ulum Jember dengan jumlah 25 Siswa dan sampel yang digunakan dalam peneltitian ini yaitu seluruh kelas V dalam satu kelas dengan design One-Grub Pretest-Posttes serta dilanjutkan dengan uji t-tes.

\section{PEMBAHASAN}

Tujuan dalam penelitian ini untuk mengetahui Pengaruh media Audio Visual terhadap keterampilan menulis siswa kelas V MI Miftahul Ulum.

Penerapan media audio visual yang dilaksanakan pada kelas eksperimen yaitu dengan penampilkan (Video kartun dengan melafalkan kata benda sesuai isi materi yang berada di Perpustakaan Sekolah) siswa diperintahkan untuk memprhatikan dan memperhatikan video ditayagkan oleh guru, dan proses pembelajaran sangat aktif dengan media video Visual. Sehingga media audio visual berpengaruh terhadap interaksi siswa dengan guru maupun antara siswa dengan siswa yang lain.

Setelah siswa meperhatikan dengan baik Video kartun yang di tampilkan oleh guru, kemudian guru menjelaskan kembali kandungan isi film tersebut sehingga antara guru dan siswa saling bertanya jawab untuk memahaminya. Langkah selajutnya, guru memberikan tes keterampilan menulis dengan cara menuliskan kembali pelafan yang disampaikan oleh guru dengan tepat dan benar. Hal ini membuat siswa lebih aktif dan terlibat langsung dalam proses belajar mengajar sehingga suasana saat proses pembelajaran menjadi lebih menyenangkan dan kondusif serta lebih mudah menerima feedback yang diberikan oleh guru.

\footnotetext{
${ }^{11}$ Sugiyono, Metode Penelitian Kuantitatif Kualitatif dan $R \& D, 74$

12 Moh. Nazir, Metode Penelitian (Bogor: Ghalia Indonesia, 2017), 205
}

Hasil rekapitulasi menunjukkan nilai posttes maharoh kitaba dengan audio visual yaitu niali tertinggi adalah 90 dan nilai rendahnya 70 , sedangkan hasil pretest nilai tertinggi 80, dan rendah 50. Berdasarkan hasil analisis penggunaan media audio visual yang diterapkan pada pembelajaran Bahasa Arab untuk maharoh kitaba lebih baik daripada tidak menggunakan media audio visual.

Berdasarkan $t_{\text {hitung }}=2.552 \mathrm{dan} t_{\text {tabel }}$ pada $\alpha=5 \%$ dan $\mathrm{dF}=25=0,413$ menujukkan t hitung $\geq \mathrm{t}$-tabel sehingga $2.552 \geq 0,413$ maka Ho diterima.

Kesimpulan dari permasalahan yang di ajukan ada pengaruh media pembelajran audio visul terhadap maharoh kitabah siswa kelas V MI Miftahul Ulum, Arjasa, Sukowono Jember Tahun Pelajaran 2019/2020.

\section{SIMPULAN}

Berdaarkan hasil analisis data yang dilakukan dapat disimulkan bahwa penggunaan media audio visual berpengaruh terhadap maharoh kitabah siswa kelas V Miftahul Ulum Arjasa, Sukowono Jember disebakan nilai rata-rata maharoh kitabah dengan menggunakan media pembelajran audio visual pada kelas $\mathrm{V}$ yaitu nilai maximal mencapai 90 sedangkan rata-rata 77,4 sementara berdasarkan $t_{\text {hitung }}=2.552 \mathrm{dan} t_{\text {tabel }}$ pada $\alpha=5 \%$ dan $\mathrm{dF}=25=0,413$ Karena $\mathrm{t}$ hitung $\geq \mathrm{t}$ table hal ini menunjukkan bahwa $2.552 \geq 0,413$. Jadi dapat disimpulkan bahwa media audio visual efektif digunakan dalam pembelajaran Bahasa Arab dengan materi perpustakaan di sekolah dan dapat digunakan dalam maharoh kitabah siswa pada mata pelajaran bahasa arab pada kelas V Arjasa, Sukowono Jember tahun Pembelajaran 2019/2020.

\section{DAFTAR PUSTAKA}

Arsyad, Azhar. 2011. Media Pembelajaran. Jakarta: PT Rajagrafindo Persada. Broto, A.S. 1980. Pengajaran Bahasa Indonesia sebagai Bahasa Kedua di Sekolah Dasar Berdasarkan Pendekatan Linguistik Kontrastif. Jakarta : Bulan 
Bintang.

Munadi, Yudhi. 2013. Media Pembelajaran.

Jakarta: Refrensi GP Press Group

Musfiqon. 2012. Pengembangan Media \&

Sumber Pembelajaran. Jakarta: Prestasi

Pustaka Publisher

Mustofa, Syaiful. 2017. Strategi

Pembelajaran Bahasa Arab Inovatif.

Malang: UIN Press.

Mustofa, Bisri. \& M. Abdul Hamid. 2016.

Metode dan Strategi Pembelajaran

Bahasa Arab. Malang: UIN Maliki

Press.

Nazir, Moh. Metode Penelitian. Bogor:

Ghalia Indonesia

Sugiyono. 2015. Metode Penelitian

Kuantitatif,kualitatif dan $R \& D$ Cet. 22.

Bandung: Alfabeta. 